\title{
Emergency Caesarean Section Anesthesia in Rural Africa: Prospective Study of 195 Cases
}

\author{
Diedhiou Moustapha ${ }^{1 *}$, Dia C. A ${ }^{1}$, Dieng $\mathrm{M}^{1}$, Barboza $\mathrm{D}^{2}$, Thiam O ${ }^{1}$, Sarr N ${ }^{1}$, Diouf $\mathrm{A}^{1}$, Fall ML ${ }^{1}$
}

${ }^{1}$ Training and Research Unit in Health Sciences, Gaston Berger University Senegal, Sanar, Saint-Louis 32002, Senega

${ }^{2}$ Training and Research Unit in Health Sciences, Assane Seck University, Ziguinchor 27000, Senegal

DOI: $10.36347 /$ sjams.2020.v08i12.003

| Received: 15.11.2020 | Accepted: 24.11.2020 | Published: 05.12.2020

*Corresponding author: Diedhiou Moustapha

Abstract

Original Research Article

Objective: Evaluation of anesthetic practices during emergency cesarean sections at the regional hospital of Saint Louis in Senegal. Patients and methods: Prospective, descriptive and analytical study of 4 months (from February 1st to May 31st, 2019) including all patients who had an emergency caesarean section. The parameters studied were: age of patients, history and condition of patients, number of pregnancy and childbirth, preoperative clinical and paraclinical evaluation data, indication for surgery, types of surgery, anesthesia data, intraoperative incidents and accidents, postoperative complications, fetal and maternal morbidity. The data have been input and analyzed with the software Epi Info version 7.2.3.0. Results: We collected a total of 195 patients. The average age was 27 years (Extremes: 15 - 45 years). The preoperative evaluation found a score of ASA 1 in 41\%, ASA 2 in $31.7 \%$, and ASA 3 in $21 \%$ of cases. The initial Glasgow coma scale was 15 in $96 \%$ of cases, and variable consciousness disorders were noted in $4 \%$ of cases. Pre-operative hypertension was reported in 35\% of cases and hypotension in $2.6 \%$ of cases. Anemia with a hemoglobin level $<11 \mathrm{~g} / \mathrm{dl}$ was noted in $25 \%$ of cases. Patients received an average of $1400 \mathrm{ml}$ of crystalloids (Extremes: 500 to $2000 \mathrm{ml}$ ). Feto-pelvic dystocia, vascular and renal syndromes and acute fetal distress were indications for Caesarean section in $49 \%, 28 \%$ and $25 \%$ of cases respectively. Spinal anesthesia was the anesthetic technique in $90.3 \%$ of cases. Intraoperative complications were hypotension, bradycardia and hemorrhage, which were mostly found during general anesthesia. Conclusion: The choice of anesthetic technique must consider the degree of urgency, the maternal and fetal condition. In rural Africa, our study has revealed that, beyond scientific recommendations, organizational, environmental factors and the equipment participate in the choice of the anesthetic technique.

Keywords: Anesthesia - caesarean section - obstetrical emergencies.

Copyright $(\mathcal{C}) 2020$ The Author(s): This is an open-access article distributed under the terms of the Creative Commons Attribution 4.0 International License (CC BY-NC 4.0) which permits unrestricted use, distribution, and reproduction in any medium for non-commercial use provided the original author and source are credited.

\section{INTRODUCTION}

The practice of anesthesia in emergency situations is often feared by anesthesiologists. Caesarean delivery is associated with maternal and fetal morbidity and mortality which can sometimes involve anesthesia management. This is why the specificities of this management must be known to clinicians. The anesthetic strategy obviously depends on maternal and obstetric characteristics, but mainly on the degree of urgency of the Caesarean section [1].

With this in mind, we conducted this study whose objective was to evaluate anesthesia practices during emergency cesarean sections at the regional hospital of Saint Louis in Senegal.

\section{Material And Method}

We conducted a 4-month prospective, descriptive and analytical study (from February 1st to May 31st, 2019). The study included all patients who underwent an emergency cesarean section in the maternity ward during the study period. Criteria for non-inclusion were prophylactic Caesarean section cases, non-obstetrical emergencies, and obstetrical emergencies with incomplete records. The parameters studied were: patient age, patient history and condition, number of pregnancy and childbirth, data from preoperative clinical and paraclinical evaluation, indication for surgery, types of surgery, anesthesiology data, intraoperative incidents and accidents, postoperative complications, maternal and fetal morbidity and mortality. The data were collected on questionnaires created for this purpose. The documents used were mainly patient interviews, prenatal 
consultation notebooks, patient records, anesthesia records, and interviews with gynecologist and obstetricians. The data have been input and analyzed with Epi Info version 7.2.3.0 software. Text and tables have been made with MS Word 2013 software and graphics have been made with MS Excel 2013 software. Qualitative variables have been expressed as a percentage $(\%)$ and quantitative variables as an average. The statistical chi-square test has been used for the comparison of proportions with a significance level of 0.05 .

\section{RESULTS}

We collected a total of 195 patients in our study. The average age was 27 years. The extremes were 15 to 45 years. In our study, the absence of a medical and surgical history was found in 141 patients, i.e. in $72.3 \%$ of cases; however, 24 patients had a history of hypertension, i.e. in $12.3 \%$ of cases, 17 patients were known to be diabetic, i.e. in $8.7 \%$ of cases, and a history of sickle cell disease and asthma was reported in 2.6 and $0.5 \%$ of cases respectively. The history of caesarean section was found in 28 patients, i.e. in $14 \%$ of cases, and myomectomy was performed in 2 patients, i.e. in $1 \%$ of cases. The history of spinal anesthesia was found in 27 patients, i.e. in $13.8 \%$ of cases, and the history of general anesthesia was found in 4 patients, i.e. in $2 \%$ of cases. The pregnancy was found to be the first in $49 \%$ of cases with an average number of pregnancy of 2.53. Zero previous childbirth was found in 104 patients $(53.3 \%)$, one childbirth was found in 31 patients $(16 \%)$ and multiple childbirth was found in 29 patients $(15 \%)$. The preoperative evaluation found an ASA 1 score in $41 \%$ of cases, an ASA 2 score in $31.7 \%$ of cases and an ASA 3 score in $21 \%$ of cases. The initial clinical evaluation showed a normal state of consciousness with a Glasgow coma scale of 15 in 188 patients, i.e. $96 \%$ of the cases. Consciousness disorders of varying stage were found in 7 patients, i.e. in $4 \%$ of cases. Seizures were found in 10 patients, i.e. in $5.13 \%$ of cases. At monitoring, preoperative hypertension was found in 69 patients, i.e. in 35\% of cases, and hypotension in 5 patients, i.e. in $2.6 \%$ of cases. All patients had at least one standard check-up (CBC, PR, APTT, Blood and Rhesus group, creatinine), the other check-ups were done according to the clinical condition, and the indication for surgery. Among the biological abnormalities, anemia was the most representative with 49 patients with a hemoglobin level below 11. The extremes were 4 and $16.9 \mathrm{~g} / \mathrm{dl}$. Table 1 summarizes the biological abnormalities detected in our series. Preoperative vascular filling was done mainly with isotonic saline (63\%) and lactate ringer (37\%). Patients received an average of $1400 \mathrm{ml}$ of crystalloids with extremes of 500 to $2000 \mathrm{ml}$; in addition, colloids were required for 9 patients. The operative indications were represented mainly by foeto-pelvic dystocia, vascular and renal syndromes and acute fetal distress in $49 \%, 28 \%$ and $25 \%$ of cases respectively. Hemorrhages were the indication for emergency Caesarean section in
$19 \%$ of cases. Table 2 shows the indications for emergency Caesarean section in our series. The time to management represents the time between the gynecologist's decision to perform surgery and the patient's installation on the surgical table. For 20 patients, i.e. in $10.3 \%$ of cases, the time to management is $<1$ hour. The time of management was 1 to 2 hours in $14.9 \%$ of cases, 2 to 3 hours in $24 \%$ of cases and 2 to 3 hours in $25 \%$ of cases. Table 4 summarizes the distribution of the time to management according to the indication for surgery.

Spinal anesthesia was the technique mostly used in our study, it was performed in $90.3 \%$ of cases and general anesthesia was performed in $9.7 \%$ of cases. For spinal anesthesia, the most commonly used local anesthetic drug was Ropivacaine in $69.9 \%$ of patients.

The most commonly used hypnotic drug was propofol for $53 \%$ of patients who received general anesthesia. Nesdonal was used in $37 \%$ of cases. In our study curares were used in 16 patients, i.e. in $8.2 \%$ of the patient cases, celocurin was used in $93.7 \%$ of the cases and vecuronium in $6.3 \%$ of the cases. Intraoperative complications were reported in 74 patients, i.e. in $40 \%$ of cases. Hypotension was found in $27.7 \%$ of cases. Eleven patients received a blood transfusion with an average of 2 red blood cell bags. The use of ephedrine was necessary for 79 patients, i.e. in $40.5 \%$ of cases. Table-3 shows the prevalence of different intraoperative complications according to the anesthetic technique. In absolute value, the complications were greater during spinal anesthesia, however, the prevalence of complications was higher at the general anesthesia (115\%). Hypotension, bradycardia and hemorrhage were mostly found during general anesthesia. Transfer to postoperative monitoring room in the immediate postoperative period was carried out in $92 \%$ of cases, and 15 patients were admitted to intensive care, for a resuscitation admission rate of $7.6 \%$. The reasons for transfer to intensive care were severe bleeding in 5 patients, i.e. in $2.5 \%$ of cases, and seizure disorders in 10 patients, i.e. in $5 \%$ of cases. The outcome in resuscitation was favorable with an average duration of hospitalization in intensive care of 3 days (extremes of 2 and 5 days). Anaemia was the postoperative complication found in $38.7 \%$ of cases. Surgical revision was necessary for 2 patients with postpartum hemorrhage, i.e. in $1 \%$ of cases.

The outcome was favorable for all patients who had the surgery in emergency. The average duration of hospitalization was 5 days with extremes of 2 and 15 days. In our study, we counted 171 newborns including 6 twins and 18 antenatal deaths. The Apgar score at the first minute $<7$ was noted in 31 newborns, i.e. in $15.8 \%$ of the cases. At the fifth minute, an Apgar score $<7$ was noted in 5 newborns, i.e. in $2.5 \%$ of cases. 
Table-1: Patient Distribution by Biological Parameters

\begin{tabular}{|l|l|l|}
\hline Biological parameter & Number & Percentage (\%) \\
\hline Biological abnormality not found & 99 & 50,8 \\
\hline Anemia & 49 & 25,1 \\
\hline Hyperleukocytosis & 31 & 15,9 \\
\hline Low PR & 13 & 6,7 \\
\hline Kidney failure & 12 & 6,1 \\
\hline Thrombocytopenia & 12 & 6,1 \\
\hline Others & 9 & 4,6 \\
\hline
\end{tabular}

Table-2: Distribution of patients according to surgical indication

\begin{tabular}{|l|l|l|}
\hline Surgical indication & Number & Percentage (\%) \\
\hline Dystocia & 97 & 49,7 \\
\hline Vascular-renal syndromes & 55 & 28,2 \\
\hline Acute fetal distress & 49 & 25,1 \\
\hline Hemorrhage & 37 & 19 \\
\hline Fetal malformation & 1 & 0,5 \\
\hline
\end{tabular}

Table-3: Prevalence of the main intraoperative complications according to the anesthetic technic

\begin{tabular}{|l|l|l|l|l|}
\hline Intraoperative complications & GA & SA \\
\cline { 2 - 5 } & Number & Percentage & Number & Percentage \\
\hline Hypotension & 10 & $52,6 \%$ & 44 & $25 \%$ \\
\hline Bradycardia & 3 & $15,8 \%$ & 2 & $1,1 \%$ \\
\hline Low Oxygen level & 0 & $0 \%$ & 1 & $0,6 \%$ \\
\hline Hemorrhage & 8 & $42,1 \%$ & 3 & $1,7 \%$ \\
\hline
\end{tabular}

Table-4: Distribution of time to management according to the surgical indication

\begin{tabular}{|l|l|l|l|}
\hline Absolute emergency & Minimum & Average & Maximum \\
\hline Eclampsia & $60 \mathrm{mn}$ & $177 \mathrm{mn}$ & $7 \mathrm{~h}$ \\
\hline Uterine rupture & $34 \mathrm{mn}$ & $131 \mathrm{mn}$ & $3 \mathrm{~h} 10 \mathrm{mn}$ \\
\hline Acute Fetal distress & $11 \mathrm{mn}$ & $125 \mathrm{mn}$ & $5 \mathrm{~h} 30 \mathrm{mn}$ \\
\hline Retroplacental hemorrhage & $60 \mathrm{mn}$ & $177 \mathrm{mn}$ & $7 \mathrm{~h}$ \\
\hline Placenta Previa & $45 \mathrm{mn}$ & $52 \mathrm{mn}$ & $1 \mathrm{~h}$ \\
\hline
\end{tabular}

\section{DISCUSSION}

The classification of emergency or scheduled Caesarean sections has been modified since 1999 by Lucas into 4 categories [2]. In many French maternity hospitals, C-sections are classified according to a "redorange-green" color code depending on their degree of urgency [3]. The English category 1 (Emergent) and the French red category 1 (French) recognize a decisionretrieval time(DRT) for the child as fast as possible, set at less than 15 minutes for the red code [3, 4]. The other categories, which are urgent and do not affect fetal or maternal vital prognosis, allow DRT codes of 30 to 75 minutes and green or type 4 Caesarean sections have no urgency and can be scheduled with very long delays. Excessive speed for urgent codes can cause stress and disorganization leading to anesthesia and surgical errors. A reduction of DRT at all costs can also lead to doing an excess of general anesthesia which are riskier for patients than local anesthesia (LA). For all urgent cesarean sections, however, the 75-minute limit must be respected, since beyond this limit neonatal complications are possible $[4,5]$. In case of an extreme emergency code (Lucas 1 or Code Red), the 15-minute time limit is a maximum time limit that restricts the choice of anesthesia technique. These are circumstances in which the choice of anesthesia must consider the fetal heart rate, but also clinical criteria (maternal hemodynamics) that may threaten fetal or maternal vital prognosis. In these circumstances, Caesarean section must be performed as soon as possible and these are probably the only cases in which general anesthesia can be imposed on the local anesthesia [5]. In our study, compliance with this French or Anglo-Saxon classification of emergency Caesarean sections was difficult to apply because of the non-optimal organization and the permanent unavailability of emergency drugs. However, the avoidance of excess speed based on the systematic search for fetal cardiac activity and maternal hemodynamics, which require rapid extraction, made it possible to reduce the use of general anesthesia to $10 \%$ vs. $90 \%$ for spinal anesthesia. Our study showed that spinal anesthesia was the technique performed in $90 \%$ of cases. Indeed, the choice of anesthesia technique in case of emergency cesarean section must consider the degree of urgency (Lucas, or code red-orange-green), the fetal cardiac activity and the maternal condition (hemodynamic, respiratory and/or neurological). Certain measures must be taken regardless of the type of anesthesia performed. Thus, after the measurements and identity checks, the control of the platelet level and the coagulation test prescribed according to the anamnestic and clinical data, blood grouping and the search for irregular 
agglutinins must be systematic [6]. In all cases, the patient is informed of the risk of blood transfusion. Anxiolytic premedication may be given at the request of the patient, but whether hydroxyzine or a benzodiazepine, placental barrier passage is significant. The administration of a non-particulate antacid aimed at increasing gastric $\mathrm{pH}$ and thus reducing the risk of Mendelson's syndrome in case of inhalation is recommended and systematic [7]: to date, effervescent ranitidine is the galenic form most commonly used in France.

Monitoring includes at least the use of a monitoring device, a tensiometer and a pulse oximeter. Because of both the risk of hemorrhage and the rapid filling associated with LA, a good caliber venous line $\geq$ $18 \mathrm{G}$ is made. Two venous lines may be useful in the event of a major hemorrhagic risk. The usual liquid fluid is Ringer Lactate ${ }^{\circledR}$ before fetal extraction, as hydroxyethyl starch do not have marketing authorization in pregnant women. Pregnant women should be placed in a left lateral decubitus position of at least $10^{\circ}$ when lying down, in order to limit aorta and vena cava compression and its hemodynamic repercussions generated by the dorsal decubitus. A $30^{\circ}$ lift up may be associated with this position, particularly in cases where there is a risk of difficult intubation and/or obesity [8]. Antibiotic is systematic, and is more and more administered before the surgical incision rather than after cord clamping. It allows a significant reduction in the rate of endometriosis and overall maternal infectious morbidity, without modifying neonatal infectious morbidity [9]. Cefazolin $2 \mathrm{~g}$ or dalacin $600 \mathrm{mg}$ in case of slow IV allergy are recommended [10]. In our study, crystalloids were mainly used as fluids in line with the data in the literature.

Spinal anesthesia (SA) is the most widely used anesthesia technique for Caesarean section, with superiority over epidurals in terms of speed of installation and effectiveness [11]. Adapted equipment with "pencil-point" needles limits the risk of postpuncture headaches, and numerous studies have made it possible to better adapt the control of induced hypotension (hypoTA). The local anesthetics (LA) administered generate maternal hypoTA, which is the major and constant adverse effect of Spinal anesthesia in the absence of preventive measures: 50 to $90 \%$ of cases for a sympathetic level in $\mathrm{T} 4$ in the absence of appropriate management; the associated nausea and vomiting reinforce maternal discomfort. This hypoTA has a strong impact on fetal well-being by altering the uteroplacental blood flow, and, depending on its duration and severity, neonatal acidosis can be observed [12]. Preventive measures for post SA hypotension include first of all puncture in a sitting position, on a pillow, with the patient wearing an elastic compression stocking. It is recommended to combine rapid filling with 10 to $15 \mathrm{ml} . \mathrm{kg}-1$ crystalloids during the execution and installation of anesthesia [13]. The two vasopressor agents used in this indication are ephedrine and phenylephrine; while norepinephrine has been studied recently, it is not currently recommended due to lack of data. Ephedrine alone is of low efficacy at low doses (<10 mg) while higher doses expose to high blood pressure and fetal acidosis (>15-20 mg). Phenylephrine has therefore been introduced as a first-line vasopressor in scheduled Caesarean sections. The use of an ephedrine/phenylephrine mixture has also been proposed and could find an indication in emergency Caesarean section in particular [11]. In our series, hypoTA controlled by ephedrine boli was the most common intraoperative complication; phenylephrine was not available in our hospital. However, our data do not allow us to correlate the existence of fetal acidosis, which would result in a drop in the Apgar score, with the exclusive use of ephedrine in our series.

The use of a Local Anesthetic drug combined with a short-acting morphine and low-dose morphine allows in most cases to perform a caesarean section under SA safely and to anticipate postoperative pain. The main Local Anesthetic drug with marketing authorization for use in SA are bupivacaine $5 \mathrm{mg}$. $\mathrm{mL}-1$ hyperbaric, Ropivacaine and levobupivacaine $5 \mathrm{mg}$. mL-1 isobaric. The addition of morphine such as fentanyl and sufentanil improves the quality of anesthesia while reducing the dose of Local Anesthetic drug required and the adverse effects including hypoTA [18]. The widespread use of obstetric epidural analgesia (OEDA) during labor, reaching about $80 \%$ of cases in France, explains the high proportion of cesarean sections performed under epidural anesthesia, 36\% [16]. OEDA for Caesarean section has the advantage of leading to fewer intraoperative maternal hypotensive episodes than SA and thus ensures better neonatal status [17]. Conversion from analgesic epidural to surgical epidural is only possible if the delay between decision and fetal extraction is greater than ten minutes for emergency Caesarean section. Semi-urgent or elective Caesarean section is the indication of choice for conversion from OEDA to surgical EDA [11]. In our study no epidural anesthesia technique was performed.

General anesthesia is essentially indicated for contraindications and Local SA failures: puncture site infection, hemostasis disorders, intracranial hypertension, hemodynamic instability (especially in septic context), severe maternal hemorrhage. GA remains the type of anesthesia recommended in extreme emergencies and when no Local SA is done. Refusal of Local SA by the patient is also an indication for GA [11]. Efficient preoxygenation with a target exhaled oxygen fraction $>90 \%$ is essential. Induction only begins once the surgeons are dressed and set up, ready to make the incision. The sequence combines Sellick maneuver, hypnotic injection, loss of ciliary reflex, and curare injection. The hypnotic recommended in the absence of contraindications remains thiopental at a 
dosage of 5 to 7 mg.kg-1 of theoretical weight to limit the hemodynamic repercussions. After the loss of the ciliary reflex, curare is administered. Suxamethonium is the recommended curare, in the absence of contraindication, at a dosage of $1 \mathrm{mg} \cdot \mathrm{kg}-1$ of current weight. Rocuronium is the alternative to suxamethonium [19] in cases of proven allergy to suxamethonium, major allergic conditions with a history of intraoperative accident, major atopic conditions, exacerbated asthma, hyperkalemia. Propofol can be an alternative to thiopental at the reduced dose of 2.5 mg.kg-1 to limit the hemodynamic effects, including hypotension. Opiates are not administered for induction in the context of rapid sequence induction, unless there is a specific indication where hypertension generated by intubation is deleterious, and in this indication remifentanil is of interest [20]. However, sufentanil remains the most commonly used morphine after fetal extraction. Maintenance of curarization is not systematic. It is carried out under the cover of curarization monitoring and an antagonization at the end of the surgery if necessary. In our study the sequence of rapid sequence induction was respected and the choice of hypnotics and curares certainly consider scientific recommendations, but in this rural African environment, the choice depended mainly on the availability of products.

\section{CONCLUSiON}

The practice of anesthesia for emergency cesarean section requires a good knowledge of algorithms and scientific recommendations. The choice of the anesthesia technique must consider the degree of urgency, the maternal and fetal condition. In rural Africa, our study has revealed that, beyond scientific recommendations, organizational and environmental factors and the equipment participate in the choice of the anesthetic technique.

\section{REFERENCES}

1. Le Gouez A, Bonnet MP. Anestesia para cesárea. EMC-Anestesia-Reanimación, 2016; 42(1), 1-11.

2. Lucas DN, Yentis SM, Kinsella SM, Holdcroft A, May AE, Wee M, Robinson PN. Urgency of caesarean section: a new classification. Journal of the Royal Society of Medicine. 2000 Jul;93(7):346-50.

3. Dupuis O, Sayegh I, Decullier E, Dupont C, Clément HJ, Berland M, Rudigoz RC. Red, orange and green Caesarean sections: a new communication tool for on-call obstetricians. European Journal of Obstetrics \& Gynecology and Reproductive Biology. 2008 Oct 1;140(2):206-11.

4. NICE Clinical Guidelines. Caesarean Section. 27 Sussex Place, Regent's. Park, London NW1 4RG: Published by the Royal College of Obstetricians and Gynaecologists; 2011 Site web: www.rcog.org.uk.

5. Chassard D, Bouvet L. Caesarean section anesthesia. Anesthesia \& Resuscitation, 2015;1(1), 10-18.
6. Formalized expert recommendations. Systematic preintervention reviews. FSSR, 2012.

7. Paranjothy S, Griffiths JD, Broughton HK, Gyte GM, Brown HC, Thomas J. Interventions at caesarean section for reducing the risk of aspiration pneumonitis. Cochrane Database of Systematic Reviews. 2014(2).

8. Soens MA, Birnbach DJ, Ranasinghe JS, Van Zundert A. Obstetric anesthesia for the obese and morbidly obese patient: an ounce of prevention is worth more than a pound of treatment. Acta anaesthesiologica scandinavica. 2008 Jan;52(1):6-19.

9. Costantine MM, Rahman M, Ghulmiyah L, Byers BD, Longo M, Wen T, Hankins GD, Saade GR. Timing of perioperative antibiotics for cesarean delivery: a metaanalysis. American journal of obstetrics and gynecology. 2008 Sep 1;199(3):301e1.

10. Professional information. Antibioprophylaxis in Surgery and Interventional Medicine (Adult Patient). Update 2010.

11. Mishra S, Ansari KM, Dwivedi PD, Pandey HP, Das $M$. Occurrence of deoxynivalenol in cereals and exposure risk assessment in Indian population. Food control. 2013 Apr 1;30(2):549-55.

12. Bonnin M, Storme B, Fournet-Fayard A. Caesarean section anesthesia: the main methods and their indications. Pain and Analgesia, 2016; 29(2), 88-93.

13. Mueller MD, Brühwiler H, Schüpfer GK, Lüscher KP. Higher rate of fetal acidemia after regional anesthesia for elective cesarean delivery. Obstetrics \& Gynecology. 1997 Jul 1;90(1):131-4.

14. Mercier FJ. Cesarean delivery fluid management. Current Opinion in Anesthesiology. 2012 Jun 1;25(3):286-91.

15. Blondel B, Lelong N, Kermarrec M, Goffinet F. Coordination nationale des Enquêtes Nationales Périnatales. La santé périnatale en France métropolitaine de 1995 à 2010. Résultats des Enquêtes Nationales Périnatales. J Gynecol Obstet Biol Reprod. 2012;41(2):151-66.

16. Sellick BA. Cricoid pressure to control regurgitation of stomach contents during induction of anaesthesia. Lancet, 1961; 2:404-6.

17. Tonni G, Ferrari B, De Felice C, Ventura A. Fetal acidbase and neonatal status after general and neuraxial anesthesia for elective cesarean section. Int J Gynaecol Obstet. 2007; 97:143-6.

18. Demiraran Y, Ozdemir I, Kocaman B, Yucel O. Intrathecal sufentanil $(1.5 \mu \mathrm{g})$ added to hyperbaric bupivacaine $(0.5 \%)$ for elective cesarean section provides adequate analgesia without need for pruritus therapy. Journal of anesthesia. 2006 Nov 1;20(4):274-8.

19. Perry JJ, Lee JS, Sillberg VA, Wells GA. Rocuronium versus succinylcholine for rapid sequence induction intubation. Cochrane Database Syst Rev, 2008; CD002788.

20. Van de Velde M. The use of remifentanil for cesarean section. Current Opinion Anaesthesiol. 2016; 29:257-60. 